\title{
Postgraduate Science Research Skills: the role of creativity, tacit knowledge, thought styles \& language
}

Jenny Marie ${ }^{1}$

$U C L, U K$

This paper analyses three crucial research skills: problem identification, data collection and hypothesis-formation. It concludes that science research students should be taught about the creative process as science students are under pressures that can inhibit creative thought. They should also be taught the importance of tacit knowledge for learning how to do research, as this will aid the process. Styles of thought and language allow researchers to identify and solve problems and limit what the latter can be. Students may benefit from further knowledge of these, so they can understand why their interpretations differ from others and how to create truly original hypotheses. The paper calls for further research into the relationship between language and hypothesis-formation.

Keywords: research skills; creativity; tacit knowledge; styles of thought; language.

\section{Introduction}

In 2001 the UK Research Councils issued a joint statement of the skills they expect the doctoral research students they fund to obtain during the course of a postgraduate degree. The statement consists of seven categories of skills, namely research skills

${ }^{1}$ Centre for the Advancement of Learning and Teaching, UCL, 1-19 Torrington Place, London, WC1E 7HB. E-mail: j.marie@ucl.ac.uk 
and techniques (including problem forming and solving), research environment (including awareness of the commercial, ethical and international context of the research), research management (including project and resource management), personal effectiveness (including identification of training needs, independence and initiative), communication skills (including written and oral communication and the defence of ideas), networking and teamworking (including the establishment and maintenance of links with useful contacts) and career management (including the effective representation of skills and experiences through a CV) (Research Councils, 2001).

In 2002 Sir Gareth Roberts's review of the supply of science and engineering skills in the UK reported that $\mathrm{PhD}$ students were not acquiring the skills they needed to fulfil their long-term needs (Roberts, 2002, summary of chapter 4).

In response to the Roberts Review, the UK government made $£ 29.4 \mathrm{~m}$ available to the Research Councils to support skills development. As the money has filtered through, the HE sector has seen a proliferation of skill development courses for postgraduate students. The provision of these courses has been guided by the Research Councils' Joint Skills Statement (JSS) and the Research Councils expect the students they fund to receive two weeks worth of skills training per annum. Nevertheless, most of these courses are focused on transferable skills (the last four of the JSS categories of skills) as opposed to research skills (the first three of the JSS categories).

The lack of courses for the development of research skills does not mean that the HE sector is not developing these skills, but it indicates that we are probably not paying as much attention to their development. This paper will not argue for an increase in courses aiming to teach research skills. Its aim is to raise awareness of the 
issues involved in promoting research skills, so that this may be done more effectively wherever it is done.

The lack of attention being paid to the development of research skills is in some ways curious. There is a wide range of literature that considers transferable skills development and how to gain a PhD. Understanding of scientific research skills should also benefit from the work of philosophers, sociologists and historians of science.

There is some work in the field of science education that draws on this body of knowledge. David Kaiser, for example, has tried to call the attention of those in science studies to the question of science education (Kaiser, 2005, p. 3), and he and Andrew Warwick have started to look at the insights Thomas Kuhn and Michel Foucault's work can provide for the training of researchers (Warwick and Kaiser, 2005). While the science education literature clearly recognises that history and philosophy of science is informative about the nature of science, it has mainly confined itself to recommending that it should therefore be taught as part of the science curriculum (see, for example, Kipnis, 2006; Matthews, 2000; Solomon, 2002), rather than seeing it as a means to gaining a better understanding of how universities should be training researchers.

More work like that of Warwick and Kaiser is required to integrate this body of knowledge with theories about learning in HE to form a coherent understanding of the development of research skills. In this paper, I aim to synthesise these ideas so as to analyse what some of the JSS research skills entail and how they can be developed. I will focus particularly on their development in science students because the wider range of literature on scientific research means that their application to science 
students appears to be a good starting point for considering their development more generally.

Furthermore, there is a particular need for science research students to learn how scientists practice. As Robert Bargar and James Duncan have argued, scientific work is often reported to have occurred in a manner that has been post-rationalised. This can harm the development of postgraduate science students in two ways. Firstly, it can prejudice them against apparently subjective thought processes that are vital for creative thought (Bargar and Duncan, 1982, pp. 2, 4). Secondly, students can become disillusioned with research because it is more complex and time consuming than they have been led to believe (Collins, 2007, p. 221).

Social science research students already have to be reflexive. As Pierre Bourdieu has argued since social science is a socially constructed account of social construction, it must take itself as an object of study (Bourdieu, 2004, p.88 see also Bloor, 1991, p. 7). One aspect of this is to consider how the researcher himself impacts the research being done (Denscombe, 1998, p. 212). Science students need to have a similar awareness of how scientists practice, not to enable them to be selfcritical, but because it will help them to develop their research skills.

The JSS lists 17 research skills. It lies beyond the scope of this paper to consider how all of these skills can be developed. I have chosen instead to focus on the three research skills that I consider most important: "the ability to recognise and validate problems," the ability to "design and execute systems for the acquisition and collation of information through the effective use of appropriate resources and equipment" and the ability to demonstrate "original, independent and critical thinking, and the ability to develop theoretical concepts" (Research Councils, 2001, paragraphs A and C). 


\section{Analysing the skills}

The three research skills chosen from the JSS share a couple of characteristics with each other. Firstly, none of them are single, integral skills, when a skill is understood to be an ability to perform a function. They all involve the transferable skills of critical thinking and creativity. They also involve disciplinary knowledge, tacit knowledge, language skills and thought styles.

The integral place that disciplinary knowledge has in these research skills immediately dismisses any possibility of generic courses replacing the learning of them in individuals' own departments. However, while the knowledge content associated with these skills may be disciplinary, the process of developing them has some common features across disciplines. This process involves developing students' tacit knowledge, learning how to create knowledge and the development of critical thinking and creativity. These may be areas that generic courses could address.

\section{Problem identification}

Unlike their counterparts in the social sciences and humanities, science research students rarely define their own research problem. Science projects usually involve expensive equipment and/or materials and so the application for funding is made by an academic member of staff before the university accepts students to work on the project for their research degree (Cryer, 2006, pp. 26-27). A science student may therefore be faced with the prospect of having to identify a new research problem for the first time when he wishes to apply for a postdoctoral position. As this is highly 
likely to coincide with the stressful period of writing up and trying to complete the degree on time, science students may need a level of help and support defining a research problem, which perhaps seems incommensurable with their final year status. It is therefore important that their supervisors have a good understanding of the different ways in which problem identification occurs.

When planning their postdoctoral work, students may wish to generate a number of ideas as to their next project, so as to select the most attractive to them (for researchers' choice of problems see Brew, 2001, chapter 6). To enhance this process it is worth understanding a little more about creativity. Geoffrey Petty has described the creative process as having six stages: inspiration, clarification, evaluation, distillation, incubation and perspiration (Petty, 2007. For the importance of creativity to scientific doctorates and how it can be supported, also see Bargar and Duncan, 1982). In the first of these stages a huge number of ideas are created. Postponing the evaluation of ideas at this stage enhances this process. The objective must then be clarified (to come up with a productive problem that can be worked on with $\mathrm{x}$ resources) and the ideas evaluated, such that good ideas are distilled out. Ideas are then left alone before the hard work starts on developing them further.

This process is helpful in as much that it is worth knowing that the inspiration stage is helped by being relaxed and by postponing the evaluation of ideas until it is over. However, other tools often help this part of the process. For creating research problems, such a tool would be an understanding of the types of problems there are. I have identified six types of problem, though there may well be many more:

(1) A theory from one area can be adopted and the problem is how to apply the theory in a new area. 
(2) Two theories can be juxtaposed and the problem is the resolution of their inconsistencies.

(3) A new discovery can be made and the problem is to consider the implications this has for the area.

(4) An unexpected piece of data is reliably gathered and the problem is to explain it.

(5) Nothing can be known about an area and the problem is to 'chart the waters'.

(6) An external demand is created for implicit knowledge to be made explicit.

The evaluation stage of problem identification is interesting in as much that part of it involves validating the problems (a specific part of the JSS problem identification skill). Is the problem real, or does it rely on a misconception, or lack of information about existing knowledge? Is it meaningless, trivial or of real value to the scientific community?

Evaluation, and validation, goes beyond this. Evaluation would also involve considering whether resolution of the problem is likely, given the resources available for tackling it. These feasibility issues are dealt with in the myriad of $\mathrm{PhD}$ handbooks that exist. They also consider the vexed issue of originality, which is another important consideration for evaluating potential research problems (see, for example, Sharp and Howard, 1996, pp. 24-42). Evaluation and validation also both involve consideration of how productive tackling the problem is likely to be.

Michael Polanyi rendered the evaluation of a problem's potential for being productive problematic. He claims that it involves foresight. He wrote: "To see a problem that will lead to a great discovery is not just to see something hidden, but to 
see something of which the rest of humanity cannot have even an inkling" (Polanyi, 1983, p. 22). This led Polanyi to refer to the problem Plato set, that a problem either involves us knowing what we are looking for, in which case there is no problem, or us not knowing what we are looking for, in which case we cannot hope to find anything. He claims that the solution to this is that we do know what we are looking for but only tacitly.

Tacit knowing is defined by Michael Polanyi as knowing 'more than we can tell' (Polanyi, 1983, p. 18). He describes how tacit knowing involves attending from a proximal term to a distal term. The example Polyani gives is of a blind man, who uses his knowledge of how his stick's resistance changes as he moves it to gain knowledge of his surroundings. The stick's resistance is the proximal term, while the surroundings are the distal term. The blind man attends to the surroundings and thus gains knowledge he can tell about them, but he does not attend to the stick's changing resistance and thus gains tacit knowledge of it. Polanyi describes this tactic knowledge as a subsidiary awareness of the particulars (the stick's resistance) that enables the person to have knowledge of the whole (Polanyi, 1958, pp. 55-58).

Polanyi does not analyse the tacit knowledge involved in problem-setting in the vocabulary of proximal and distal terms, which leaves me feeling discontented with his explanation. How do we gain tacit knowledge of the problem's solution? The following is thus my interpretation of how Polanyi's concept of tacit knowledge would apply in this situation. In the context of evaluating a research problem, the proximal term is the explicit knowledge that the researcher already has about the discipline. The solution to the problem is the distal term. The researcher is attending to the knowledge he has, but he has an awareness beyond this. To solve the problem then, he must make this tacit knowledge explicit by gradually changing the focus of 
his attention. (Support for this interpretation comes from Polanyi's contention that the theories we use to understand the world are interiorized and we attend from them to the world. (Polanyi, 1983, p. 17)).

For this to be a solution to the problem, the researcher could not know he had tacit knowledge of the problem's solution. This seems epistemologically problematic to me because no evidence could be brought forward for its existence, other than it being a logical solution to Plato's problem. I am not criticising the concept of tacit knowledge here, as I discuss in the next section this is important to research practice. However, I am questioning whether researchers have tacit knowledge of problems' solutions. Empirical research seems to me to necessitate that the solution is undefined prior to the research being carried out, because the researcher cannot know what results he will gain.

As it happens there is another possible solution to Plato's problem. It may be that we do not know what we are looking for but we are restricted in what we can find and thus can hope to find something. An analogy would be a blindfolded child trying to find something in a closed room. He does not know what he will find, and may walk straight past the nearest object. However, he is restricted by the room's walls and what he can feel (air would be transparent to his touch). He may be guided by any noises objects made, but he would still need to touch them in order for the object to be found. The scientist is limited in what he can find to phenomena that he can make consistently reproducible, even if guided by other signs. He is limited in the range of his search, not only by the problem he has set, but also by his thought style.

A thought style is a way of thinking that constrains an individual's thoughts and perceptions, without him really being aware of its existence. It constrains what he considers to be an acceptable problem to explore and what he would recognise as a 
legitimate solution. While this sounds negative, Ludwik Fleck defined a thought style as "[the readiness for] directed perception, with corresponding mental and objective assimilation of what has been so perceived." (Fleck, 1979, p. 99, emphasis in original). An individual needs a thought style in order to be able to make observations and hypotheses - because it creates the rules as to what counts as an observation or hypothesis.

Fleck continued on by writing:

"It [a thought style] is characterized by common features in the problems of interest to the thought collective [a community sharing a thought style], by the judgment which the thought collective considers evident, and by the methods which it applies as a means of cognition. The thought style may also be accompanied by a technical and literary style characteristic of the given system of knowledge" (Fleck, 1979, p. 99).

A thought style is thus the tacit rules as to what counts as physiology, organic chemistry, quantum mechanics etc.

Fleck has described how productive research experiments tend not to be well defined - the scientists do not know what they are looking for. However, they find something because their thought style limits the ways they can interpret their results (Fleck, 1979, pp. 86-92). We are starting to enter into a discussion of how problems are solved now, rather than how they are set. Further discussion of thought styles is therefore deferred to the section on problem solving. The important point here is that this solution to Plato's problem does not involve tacit knowledge of the solution.

Whether evaluation occurs via tacit knowledge of the solution or whether a problem's solution arises from the restrictions rendered by the person's thought style is an important question. If it is due to tacit knowledge, then students should be 
aiming for well-defined problems. If solutions arise from their thought style, as I think, problems should not be too well defined or there is not room for the occurrence of unexpected phenomena. However, the less defined the problem the more demanding reaching a solution will be on the student's hypothesis-creation skills. A safer strategy is a well-defined project with a limited number of possible solutions.

\section{Data collection}

Data will normally be collected through both a literature search (also important for evaluating the problem's originality) and via experimentation. The literature research involves a number of transferable skills, such as library skills and note taking. By reading and relating the material to the identified problem, the problem is further refined.

For a research student, the experimental set-up will probably come from papers or the individual's supervisor. The instructions come in the form of words (written or oral), yet words can only represent the reality of doing such as set-up. Like any representation it is not complete because it is not the thing itself. Parts of this knowledge cannot be passed on through words but by watching other practitioners and copying them. Harry Collins has identified five types of knowledge about practice that can be passed on by personal contact rather than through language (Collins, 2001, p. 72). One of these does not apply in this situation: information that the practitioner does not want to reveal. However, the other four do: knowledge that neither party realises needs to be passed on, ostensive knowledge, unrecognised knowledge and uncognized or uncognizable knowledge (though Collins questions the ontological existence of the latter). 
Knowledge that neither party realises needs to be passed on arises when the practitioner does not realise that the student needs to be told to do something in a certain way and the student does not know what questions to ask. Ostensive knowledge is that which it is very hard to represent through language - it is knowledge of how something feels or looks (the whole, which cannot be adequately represented by the parts focused on when a diagram is drawn). Unrecognised knowledge is knowledge that something is done in a particular way without realising its significance - in an experiment there are so many variables that the importance of some of them may be overlooked. Uncognized knowledge includes such things as the grammatical rules of your mother-tongue, which you would have difficulty putting into words. Here knowledge has been gained through practice and is passed on in this way. Some of this knowledge could be formalised, just as foreign languages are normally learned with explicit knowledge of the grammatical rules. However, the practice is never as fluid until the explicit knowledge is used tacitly in practice.

Polanyi describes the process of making such explicit knowledge tacit as interiorization of the knowledge. For abstract knowledge relating to practice, true grasp of the knowledge is not in making it explicit but in its use. Polanyi claims that making the knowledge explicit will destroy its use in practice. In some cases, the skill will become better than it originally was when this process is followed by practice but in other cases the damage is irreparable (Polanyi, 1983, pp. 17-19). Lev Vygotsky's finding that children speak when trying to solve practical problems backs this up. Children are learning how to problem solve - adults who are competent practical problem solvers do not need to explicitly think what to do. Vygotsky also found that children are less spontaneous when they can speak, thus explicitly knowing what to do inhibits the spontaneity that gives practice its fluidity (Vygotsky, 1978, pp. 25-26). 
The link between tacit knowledge and practice is strong. Practice involves doing therefore it is bound to include some ostensive knowledge. It also includes procedural knowledge, which means that the practice will be more fluid when that knowledge is tacit. Such knowledge must therefore either be learned or internalized (which is another form of learning) through practice.

This means that learning how to do an experiment will require the research student to watch someone else practice and then try to copy them. Furthermore, Collins argues that the importance of tacit knowledge to research practice makes it important that new practitioners explicitly know; firstly how important tacit knowledge is as this will ease its transfer and secondly how difficult learning practice is or students will distrust claims that it can be done (Collins, 2001, pp. 81-82).

I teach a number of research students about the premises of research and how to develop their transferable skills. Not so long ago one of them reported to me that she was a slow learner. This surprised me greatly, as it was contrary to all my experience of her. I therefore asked her for evidence of this. She replied that it was taking her a long time to get the experimental set-up right. I asked if it had occurred to her that perhaps that is how long it takes to set up an experiment. She looked a bit uncomfortable and said "maybe" in an exceedingly unconvinced fashion. Learning that the development of practice takes time is an important lesson for new practitioners of research and, despite its simplicity when stated explicitly, it appears to be a very difficult lesson for them to learn.

Gaining results is not just about being able to follow an experimental set-up, it also involves observation. All observations involve some form of interpretation. Fleck gives the example of "Today one hundred large, yellowish, transparent and two smaller, lighter, more opaque colonies have appeared on the agar plate" and asks how 
the person knows they are separate colonies (Fleck, 1979, p. 90). There is also information missing: what the colonies felt like, tasted like etc. This information is judged unimportant, due to the fact it cannot be interpreted in the light of previous knowledge.

Fleck does not see these assumptions as problematic. On the contrary, Fleck claims that what makes someone a professional scientist is that he makes the same assumptions as other professional scientists and he does so due to his training. This, communally shared, way of perceiving is a major constituent of a thought-style (Fleck, 1979, pp. 90-92).

As Etienne Lave and Jean Wenger point out people learn to be a member of their community (and thus share the community's thought-style) by participating in it (Lave and Wenger, 1991). The focus again, is not on being taught but on observing, copying and doing.

\section{Developing hypotheses}

One of the most important skills a researcher must have is covered by the JSS's requirement for researchers to be able to demonstrate "original, independent and critical thinking, and the ability to develop theoretical concepts" (Research Councils, 2002, paragraph A).

Creativity is vital to hypothesis formation. However, because science is usually portrayed as a rational, objective process, students and their supervisors may view creative thought as inappropriate. It is therefore helpful to separate the generation of possible explanations from their later justification. Bargar and Duncan's study of scientists' autobiographies reveal that in generating possible explanations 
successful scientists often use imagery, metaphors, analogies and hunches. Furthermore, insights often occur following hard work on a problem, when the researcher is consciously not attending to the problem in question (Bargar and Duncan, 1982, pp. 3-4, 6-8). Especially in the later phases of a research project, students can inhibit creative thought by trying too hard to come up with a solution. If they are not open to the insights that come from more subjective ways of thinking, the solutions they generate will be mechanical.

As in Petty's description of the creative process, the evaluation of possible explanations should come after their generation (Petty, 2007). It is in evaluating the ideas that the student needs to use logical analysis to judge whether his ideas fit existing theory and provide rational explanations for the phenomena in question, not during their generation (Bargar and Duncan, 1982, p. 3).

The researchers' thought style will have a vital role to play in his evaluation of the possible explanations because it defines what a person considers to count as an explanation in his discipline. Part of scientific thought styles is that the explanation must logically explain the experimental results gained and fit existing ideas about how the world works. This conception of the world is what Thomas Kuhn termed a disciplinary matrix (Kuhn, 1970, p.184).

What can be interpreted from an experiment is thus constrained by the person's previous knowledge. Having constraints on how one can formulate hypotheses is a necessary condition of hypothesizing. Fleck describes the process of making a discovery as beginning with chaotic observations (based on the assumptions inherent in the person's thought style). He will then grope for understanding and will only begin to gain any when he meets some form of resistance, which enables the solution to take form. To create a fact, according to Fleck, is to maximise thought 
constraint, in order to prevent others from being able to interpret the data in any other way (Fleck, 1979, pp. 94-96).

Another element of thought style is the meanings that words have. People belonging to different thought collectives understand different things by the same words. They cannot either agree or disagree because they cannot have the same thought (Fleck, 1936, pp. 83-85 and Fleck, 1979, p. 100).

If words and language are part of thought style, they also constrain the hypotheses one can create. The work of Lev Vygotsky and Alexander Potebnya suggests that thought and language are linked (Vygotsky, 1978, p.33). Vygotsky's findings are less that speech and language constrain thought, and more that they free people to think of things not present in their immediate environment and to plan actions (Vygotsky, 1978, p. 26). Nevertheless, while man may not be able to think so widely without language, the limits of language hinder us thinking beyond them.

If nothing else, science demands that our discoveries are accessible to others. Our discoveries cannot be accepted without us being able to communicate them (at least to others within our scientific community). If the solution to our problem is unrepresentable in our language of choice, we must make the solution representable. This will firstly help to clarify our ideas to ourselves and secondly, enable others to accept, reject or modify them.

The clue as to how to do this comes from children. Children learn to speak by first labelling objects and then, at a later stage of development, by synthesizing these objects through speech (Vygotsky, 1978, p. 32). The first thing that a researcher must do to make something explicit that is currently unrepresentable is to label it. An example of this occurring is in Thomas Kuhn's attempts to describe science in terms 
of normal science, paradigmic thought and revolutions. Kuhn described this by redefining the word paradigm.

This example is interesting because Kuhn did not invent a new word, but a new meaning for an existing one. As Charles Bazermann points out, language is more than words. To understand each other, we must share an understanding of the meaning of words, and what they mean in the context within which they are used (Bazermann, 1988, pp. 302-303). Kuhn invented a label by creating a new context for the word 'paradigm' and defining its meaning within this context.

By creating a label, Kuhn could describe complex ideas via the label, which enabled him to then explore how these ideas interacted with others. Kuhn did not get it right first time - as Margaret Masterman famously pointed out there were twentyone different ways in which Kuhn used the term 'paradigm' in his book, The Structure of Scientific Revolutions (Masterman, 1970, p. 61).

This finding of a way through ill-defined ground is something that research students have to currently learn through practice. If we can increase our understanding of the relationship between language and hypothesizing we are likely to be more useful to students trying to grasp ideas just beyond their reach. Equally, knowledge of thought styles may help students to understand why their explanation of a phenomenon is different from someone else's.

\section{Conclusion}

The ability to recognise problems, investigate them and to create new hypotheses is far from simple. I stated at the start of this paper that these skills involved a mixture of transferable skills, disciplinary knowledge, tacit knowledge, thought styles and 
language use. These processes are not yet well understood, and the more that we come to understand them the easier it will be for us to encourage students to develop their research skills.

The practical implications coming out of this paper are the suggestion that research students are taught about creativity and the role this has in problem identification and hypothesis creation. They should learn the role of tacit knowledge in learning experimental practice, so that they understand that the key to learning it is observation and practice, rather than reading or taking oral instructions. They should learn how difficult it is to gain, so that they do not feel disheartened and lose faith in their ability to eventually make the experiments work. Students would benefit from learning about styles of thought, as this may help them to understand why they favour one explanation, while others favour others. Research students would also benefit from learning more about how researchers create and communicate original ideas. It may be necessary for us to understand more about this ourselves, before we can teach it to students. However, we can teach them how difficult it is to capture elusive concepts. This should lead them to expect revisions, but in doing so we must be careful that they do not lose sight of the fact that there will come a time when they need to publish and let go of their ideas.

\section{Acknowledgements}

My thanks go to Jason Davies for his comments on this paper, to the two anonymous peer-reviewers for their useful suggestions and to those members of the Centre of the Advancement of Learning and Teaching that commented on the ideas at a departmental seminar. 


\section{Notes on contributors}

Jenny Marie is a teaching fellow in the Centre for the Advancement of Learning and Teaching at UCL, where she facilitates the development of transferable and research skills. She has a $\mathrm{PhD}$ in the history of biology and is an honorary fellow of the department of Science and Technology Studies.

\section{References}

Bargar, Robert R. and Duncan, James K. (1982) Cultivating Creative Endeavor in

Doctoral Research, The Journal of Higher Education, 53(1): 1-31.

Bazerman, C. (1988) Shaping Written Knowledge: The Genre and Activity of the Experimental Article in Science (Madison and London, The University of Wisconsin Press).

Bloor, David (1991) Knowledge and Social Imagery (Chicago and London, The University of Chicago Press).

Bourdieu, Pierre (2004) Science of Science and Reflexivity (Cambridge, Polity Press). Brew, A. (2001) The Nature of Research: Inquiry in academic contexts (London and New York, Routledge).

Collins, H. (2001) Tacit Knowledge, Trust and the Q of Sapphire, Social Studies of Science 31(1), 71-85.

Collins, H. (2007) The Uses of Sociology of Science for Scientists and Educators, Science and Education, 16(3): 217-230. 
Cryer, Pat (2006) The Research Student's Guide to Success (Maidenhead, Open University Press).

Denscombe, Martyn (1998) The Good Research Guide for small-scale social research projects (Buckingham and Philadelphia, Open University Press).

Fleck, L. (1936) The Problem of Epistemology, reprinted in R.S. Cohen and T.

Schnelle (1986) Cognition and Fact: Materials on Ludwik Fleck (Dordrecht, Boston, Lancaster and Tokyo, D. Reidel Publishing Company).

Fleck, L. (1979) Genesis and Development of a Scientific Fact (Chicago and London, The University of Chicago Press).

Kaiser, David (2005) Introduction: Moving Pedagogy from the Periphery to the Center, in Kaiser, David (Ed.) Pedagogy and the Practice of Science (Cambridge, Mass. and London, The MIT Press), 1-8.

Kipnis, Nahum (2007) Discovery in Science and in Teaching Science, Science and Education, 16(9): 883-920.

Kuhn, T.S. (1996) The Structure of Scientific Revolutions (Chicago and London, The University of Chicago Press).

Lave, J. and Wenger, E. (1991) Situated Learning: Legitimate peripheral participation (Cambridge, Cambridge University Press).

Masterman, M. (1970) The Nature of a Paradigm, in Lakatos, I. and Musgrave, A. (Eds.) Criticism and the Growth of Knowledge (Cambridge, Cambridge University Press), 59-89.

Matthews, Michael R. (2000) Time for Science Education: How Teaching the History and Philosophy of Pendulum Motion Can Contribute to Science Literacy (New York, Kluwer Academic). 
Petty, G. (2007) How to be Better at Creativity. Available online at:

www.greenfields.u-net.com/docs/home.html (accessed on 21 June 2007).

Polanyi, M, (1958) Personal Knowledge: Towards a Post-Critical Philosophy

(London, Routledge \& Kegan Paul).

Polanyi, M. (1983) The Tacit Dimension (Gloucester, Mass, Peter Smith).

Research Councils (2001) Joint Statement of Skills Training Requirements of

Research Postgraduates. Available online at:

www.grad.ac.uk/cms/ShowPage/Home_page/Policy/National_policy/Research_Coun

cils training requirements/p!eaLXeFl\#Joint\%20Statement\%20of\%20Skills\%20Train

ing\%20Requirements\%20of\%20Research\%20Postgraduates\%20(2001 (accessed on

13 April 2007).

Roberts, G. (2002) SET for Success: The supply of people with science, technology, engineering and mathematical skills. Available online at: $\underline{w w w . h m-}$ treasury.gov.uk/media/530/16/ACF614.pdf (accessed on 5 May 2006).

Solomon, Joan (2002) Science Stories and Science Texts: What can they do for our students?, Studies in Science Education, 37: 85-106.

Sharp, J.A. and Howard, K. (1996) The Management of a Student Research Project (Aldershot and Vermont, Gower Publishing Limited).

Vygotsky, L.S. Edited by M. Cole, V. John-Steiner, S. Scribner and E. Sourberman (1978) Mind in Society (Cambridge, Mass. and London, Harvard University Press). Warwick, Andrew and Kaiser, David (2005) Conclusion: Kuhn, Foucault, and the Power of Pedagogy, in Kaiser, David (Ed.) Pedagogy and the Practice of Science (Cambridge, Mass. and London, The MIT Press), 393-409. 